\title{
Corneal sensitivity in patients with leprosy and in controls
}

\author{
Laetitia C J M Hieselaar, Margreet Hogeweg, Christina L de Vries
}

\begin{abstract}
Aims-In a quantitative prospective study the corneal sensation in patients with leprosy was compared with age matched controls.

Methods-The patients with leprosy were classified as paucibacillary and multibacillary and were divided in three groups: (1) patients without clinically detectable eye pathology; (2) patients with lagophthalmos, (3) patients with signs of iridocyclitis. The corneal sensitivity was assessed with the Cochet and Bonnet aesthesiometer.

Results-There was a significant decrease in corneal sensitivity in multibacillary patients without clinically detectable eye pathology and in patients with lagophthalmos or iritis when compared with controls. A significant correlation between the loss of power of the orbicularis oculi muscle and the degree of corneal sensation loss could not be established. No significant decrease in corneal sensitivity was found in paucibacillary patients without eye pathology compared with the control group.

Conclusion-The results of this study showed that loss of corneal sensation can occur while there is no clinically detectable eye pathology, at least in multibacillary patients. Regular checkups of the corneal sensation should, therefore, be part of the routine control of leprosy patients. Health education on eye care and early warning signs should be encouraged.
\end{abstract}

(Brf Ophthalmol 1995; 79: 993-995)

An infection with Mycobacterium leprae has its effects on skin, peripheral nerves, and the eye. ${ }^{1-3}$ The pathology caused by $M$ leprae can, in general, be classified as follows:

Department of

Ophthalmology,

Academic Medical

Hospital, Maastricht,

the Netherlands

L C J M Hieselaar

Netherlands Leprosy

Relief Association, the

Netherlands

M Hogeweg

Medical Co-ordination

Secretariat,

Oegstgeest, the

Netherlands

C L de Vries

Correspondence to:

Dr Hieselaar, Department of

Ophthalmology, Academic

Medical Hospital Maastricht

PO Box 5800, 6202 AZ

Maastricht, the Netherlands.

Accepted for publication

18 July 1995 pupils, and loss of corneal sensation.

Severe corneal sensory loss is one of the potentially sight threatening lesions in leprosy. Corneal injuries will go unnoticed and may lead to ulceration or loss of the eye.
According to published reports corneal sensory loss may be found in combination with type I and II reactions, ${ }^{45}$ facial palsy, ${ }^{67}$ and in lepromatous leprosy. ${ }^{7}$ In the presence of anterior segment lesions such as subepithelial keratitis, massive infiltration of the corneal nerves, ${ }^{4}$ and chronic uveitis ${ }^{7}$ loss of corneal sensation is found as well.

Only a few studies on quantitative assessment of the corneal sensation (CS) of patients with leprosy are available. The recent study by Karaçorlu et $\mathrm{al}^{7}$ showed a decrease in corneal sensitivity in patients mainly with lepromatous leprosy. Most of these patients also showed anterior segment pathology. Therefore, there remains the question whether corneal sensory loss is a primary symptom in leprosy or whether it is mainly secondary to the other eye complications caused by leprosy.

The aim of this study is to determine whether loss of corneal sensation can occur primarily and solely in leprosy patients without clinical eye pathology or whether it occurs only in the presence of other eye symptoms due to leprosy.

\section{Materials and methods}

The study was conducted at the Mangu Leprosy and Rehabilitation Centre and surrounding clinics in Plateau State, Nigeria between September and December 1989. Leprosy patients were classified according to the Jopling-Ridley classification, modified by Leiker. ${ }^{9}$ All patients were classified in four groups: group I leprosy patients (all classifications) without visible eye pathology. These patients were 'subclassified' into group IA, paucibacillary patients and group IB, multibacillary patients; group II - leprosy patients with lagophthalmos in one or both eyes. The strength of the orbicularis oculi muscle was graded by use of the conventional voluntary muscle test ${ }^{10}$ (VMT, Table 1). We considered a VMT of $\leqslant$ III as lagophthalmos; group III multibacillary leprosy patients with acute or chronic iridocyclitis defined by the presence of posterior synechiae; group IV control patients of the general outpatient department without leprosy and with no eye pathology. Excluded were patients with other eye diseases and those who had undergone intraocular surgery. Eye examination included

Table 1 Grading of power loss of the orbicularis oculi muscle by means of the voluntary muscle test (VMT) ${ }^{10}$

\begin{tabular}{lll}
\hline VMT & Lid closure & Power of orbicularis oculi muscle \\
\hline V & Full & Full \\
IV & Full & Reduced \\
III & Full & Little/no resistance \\
II & Gap 1-4 mm & No resistance \\
I & Gap $\geqslant 5 \mathrm{~mm}$ & No resistance \\
\hline
\end{tabular}

A VMT of $\leqslant$ III was considered as lagophthalmos. 
the assessment of the visual acuity and slit-lamp examination of the anterior segment. In the field clinics this examination was done with a hand held torch and loupe. The VMT of the orbicularis oculi muscle was assessed. The corneal sensitivity was measured with the Cochet and Bonnet (C-B) aesthesiometer. ${ }^{11-14}$ Corneal sensation was tested using the tip of a nylon thread; the force exerted by the tip onto the cornea is increased in steps. The point at which the patient first feels the touch is recorded. The cornea is divided in five areas: superior, inferior, nasal, temporal, and central. Each area is measured five times. The average of all areas is considered as the corneal sensitivity. During the measurements the patient fixates on a point in the distance. The reliability of the patients was tested by bringing the nylon thread close to the eye without touching it. ${ }^{14}$ Although the C-B aesthesiometer has certain disadvantages $^{14-17}$ it is particularly suitable for use in the tropics because of its simplicity. It does, however, require some practice and clear instructions to the patients. One of the main drawbacks is that the elasticity of the nylon thread varies greatly with the humidity. This sometimes made the measuring impossible because the nylon thread was too weak. It was not possible to place the thread perpendicular to the cornea. The humidity was measured with a hygrometer in the field. The force exerted by the nylon thread under varying (controlled) humidity conditions was determined experimentally in the Netherlands. Since the diameter of the nylon thread is constant $(0.08$ $\mathrm{mm}$ ), the CS is expressed in milligrams.

After assessment of the CS the pupils were dilated in order to check for posterior synechiae as a sign of iritis.

\section{Results}

Since the CS is related to age $\mathrm{e}^{111418}$ and the majority of patients in this study population were over 40 years of age, the groups were matched by selecting patients and controls of 40 years and older, leaving 89 patients and 163 eyes. The patient data of these groups are listed in Tables 2 and 3.

A non-parametric test (Mann-Whitney) was chosen for statistical analysis of the CS since there was no normal distribution of values. Table 4 shows the results of the statistical analysis. The most striking result is the difference in CS of multibacillary leprosy patients without eye pathology (IB), compared with the

Table 2 Patient data

\begin{tabular}{lcll}
\hline $\begin{array}{l}\text { Group } \\
\text { (total) }\end{array}$ & $\begin{array}{l}\text { No of patients } \\
(89)\end{array}$ & $\begin{array}{l}\text { No of eyes } \\
(163)^{\star}\end{array}$ & $\begin{array}{l}\text { Age } \\
\text { (mean) }\end{array}$ \\
\hline IA (paucibacillary) & 8 & 16 & $41-65(54 \cdot 4)$ \\
IB (multibacillary & 19 & 34 & $40-60(49 \cdot 0)$ \\
II (lagophthalmos)t & 16 & 26 & $40-65(51 \cdot 3)$ \\
III (iritis) & 9 & 13 & $40-72(56 \cdot 9)$ \\
IV (controls) & 37 & 74 & $40-66(47 \cdot 2)$
\end{tabular}

*Three eyes were excluded because of scarring (in one), history of operation (in one), and trauma (in one). Twelve eyes (six patients) were separately divided into different groups. This has led to the fact that six patients are counted twice within the total number of patients.

†This group existed of five paucibacillary patients, 10 multibacillary patients, and one unknown patient.
Table 3 Results of voluntary muscle test (VMT) and corneal sensation assessment

\begin{tabular}{|c|c|c|c|}
\hline \multirow[b]{2}{*}{ Group } & \multirow[b]{2}{*}{$\begin{array}{l}V M T \\
\text { (patient } \times \text { power) }\end{array}$} & \multicolumn{2}{|c|}{ Corneal sensitivity ${ }^{\star}$} \\
\hline & & $\begin{array}{l}\text { Range } \\
(\mathrm{mg})\end{array}$ & $\begin{array}{l}\text { Median } \\
\text { value (mg) }\end{array}$ \\
\hline IA (paucibacillary) & $\begin{array}{l}6 \times \mathrm{rV} \\
10 \times \mathrm{V}\end{array}$ & $2-55$ & 3 \\
\hline IB (multibacillary) & $\begin{array}{l}20 \times \mathrm{IV} \\
14 \times \mathrm{V}\end{array}$ & $1-103 t$ & 5 \\
\hline II (lagophthalmos) & $\begin{array}{c}5 \times \text { III } \\
6 \times \text { II } \\
15 \times I\end{array}$ & $2-61$ & 6 \\
\hline III (iritis) & $\begin{array}{l}7 \times I V \\
5 \times I I I \\
1 \times I\end{array}$ & $2-35$ & 8 \\
\hline IV (controls) & $74 \times V$ & $1-20$ & 4 \\
\hline
\end{tabular}

*Since the diameter of the nylon thread was $0.08 \mathrm{~mm}^{2}$ in all cases, the corneal sensitivity is expressed in mg. To obtain the pressure equivalent $\left(\mathrm{N} / \mathrm{mm}^{2}\right)$ one must multiply by 0.78 pressure equivalent $\left(\mathrm{N} / \mathrm{mm}^{2}\right)$ one must multiply by 0.78
$(9.8 \times 0.08)$. + The extreme value of $103 \mathrm{mg}$ was found in one patient only.

control group (IV). This difference is highly significant ( $p$ value $<0.05$ ). The same highly significant difference in CS was found between leprosy patients with lagophthalmos (II) ( $p$ value $<0.05$ ) and leprosy patients with iritis (III) ( $p$ value $<0.05$ ) compared with the controls (IV). There is also a significant difference in CS between leprosy patients without eye pathology (I) compared with lagophthalmos (II, p value $<0.05$ ), and iritis patients (III, $\mathrm{p}$ value $<0.05)$.

There is no significant difference in CS between the controls (IV) and the paucibacillary patients without visible eye pathology (IA, $p$ value $=0.087$ ) and between the lagophthalmos (II) compared with the iritis patients (III, $\mathrm{p}$ value $=0.785$ )

Intrapatient variation was estimated by comparing the CS of both eyes for group IV: $41 \%$ of the patients showed no difference in CS between right and left eyes, $35 \%$ of the patients showed a difference of $1 \mathrm{mg}, 14 \%$ a difference of $2 \mathrm{mg}$, and in $10 \%$ of the patients a difference of $3 \mathrm{mg}$ or more was found.

To determine whether the VMT was correlated significantly with a decrease in the CS a linear regression model was made between patients with and without lagophthalmos. Patients with iritis or a combination of iritis and lagophthalmos were excluded in this analysis. There is a significant negative correlation between CS and age al1 $^{1118}$ and also between age and VMT (regression model, equation $=$ slope $-0.027, \mathrm{p}<0.01)$. In a multivariate linear regression model, in which the effect of each subject on the other is corrected for, it was found that a decrease in VMT was not significant ( $\mathrm{p}$ value $=0 \cdot 14)$ correlated with $\mathrm{CS}(\mathrm{VMT}=5 \cdot 04-0.01 \times \mathrm{CS})$.

Table 4 Statistical analysis of the corneal sensation (Mann-Whitney test)

\begin{tabular}{lll}
\hline Group & Group & $p$ Value \\
\hline Paucibacillary (IA) & Controls (IV) & 0.08 \\
Multibacillary (IB) & Controls (IV) & $0.005^{\star}$ \\
Lagophthalmos (II) & Controls (IV) & $0.001^{\star}$ \\
Iritis (III) & Controls (IV) & $0 \cdot 000^{\star}$ \\
Paucibacillary (IA) & Lagophthalmos (II) & $0.001^{\star}$ \\
Paucibacillary (IA) & Iritis (III) & $0.005^{\star}$ \\
Lagophthalmos (II) & Iritis (III) & 0.785 \\
\hline
\end{tabular}

*A p value of 0.05 or less is statistically significant. 


\section{Discussion}

This study demonstrates that the CS of paucibacillary patients without eye pathology is essentially the same as the CS of non-leprosy patients with healthy eyes. It was found that there is a significant lower CS in multibacillary patients even without visible eye pathology and in patients with lagophthalmos or iritis. This is in agreement with the results found in the literature. ${ }^{4-8} \mathrm{~A}$ possible explanation for the lower CS in multibacillary patients without visible eye pathology could be that direct infiltration of the corneal nerves causes secondary atrophy in those patients with long standing leprosy. This might be comparable with the mechanism of glove and stocking anaesthesia of the skin. In agreement with Karaçorlu et $a l^{7}$ we found corneal hypaesthesia rather than complete anaesthesia. The significant difference in CS of lagophthalmos patients compared with healthy non-leprosy patients ( $p$ value $=0.001$ ) could be explained in two ways. Firstly, lagophthalmos leads to an incomplete closure and thus to exposure and dryness of the cornea with damage to the tear film. Constant exposure to microtrauma (ultraviolet light and drying of the cornea), could then lead to a decrease in $\mathrm{CS}$ as we have found. However, a more pronounced loss of CS over the lower, more exposed, quadrants was not clear. Secondly, in a recent theory on corneal innervation it is postulated that the lower part of the cornea may be innervated by the V2 nerve (maxillary nerve), contrary to the classic knowledge that the whole cornea is innervated by the V1 nerve (ophthalmic nerve). ${ }^{1920} \mathrm{~A}$ facial type I reaction in a skin patch over the zygomatic area, innervated by the $\mathrm{V} 2$ nerve, often involves the facial nerve and leads to subsequent lagophthalmos. ${ }^{21}$ This is explained by the numerous anastomoses between the two nerve branches. If indeed the V2 nerve innervates the lower cornea, a ready explanation is offered on how lagophthalmos and corneal hypaesthesia are both the result of a type I reaction over the zygomatic area.

For both explanations one would assume a positive relation between the weakness of the orbicularis oculi muscle and loss of CS. This correlation could not be confirmed in this study, possibly because of the relatively small numbers of patients. We feel strongly that further research should be encouraged.

A significant loss in CS in group III was found in patients with signs of an acute or chronic iritis. However, six of the 13 eyes also had a lagophthalmos. Iritis is considered to be the ocular manifestation of the type II reaction in leprosy (Coombs and Gell classification type II $\left.^{1}\right)$. Therefore it is likely that during an iritis the short ciliary nerves, which enter the cornea at the limbus, are also included in the process thus leading to damage and loss of CS. This is comparable with the loss of corneal sensation in (epi-) scleritis. ${ }^{22}$ Invasion of the anterior uvea by $M$ leprae may lead to chronic iritis and may possibly damage the short ciliary nerves as well and thus lead to corneal hypaesthesia.

We realise the study has certain drawbacks. The number of patients was small because of the effect of age on CS. Most of the multibacillary population were patients with a long standing disease. This was due to the self presenting effect of the leprosy clinics. Furthermore, this was a cross sectional study instead of a longitudinal one. However, it is our opinion that this study rendered enough results to propose the following. Corneal sensory loss occurred in multibacillary patients without clinically detectable eye pathology. It also occurred secondary to eye pathology caused by leprosy which confirms the findings in the literature. It was not possible to establish whether corneal sensory loss may occur in paucibacillary leprosy patients without eye pathology due to exclusive damage of the V1 nerve by the type I reaction without lagophthalmos.

It would be useful to determine a threshold for the corneal protective sensation as an analogy for the threshold for protective sensation in the skin. All patients with diminished CS should wear sunglasses as a protective device and be given health education on self examination. Further research on corneal hypaesthesia in 'healthy' eyes and the possible relation between V2 and VII nerve damage and the corneal sensation should be encouraged.

We thank Musa Goyol, Ayuba Kezak, and Tabitha Ganah for their great help during the fieldwork.

Dr J Hermans, University of Leiden, is acknowledged for the statistical analysis of the data.

1 Brand ME, Ffytche TJ. Eye complications of leprosy. In: Hastings RC, ed. Leprosy. 1st ed. Edinburgh: Churchill Livingstone, 1985: 223-42.

2 Naafs B. Nerve pathology in leprosy. In: Prevention of permanent nerve damage in leprosy. Amsterdam: Elsevier, 1980: 22-30.

3 Hogeweg M. Leprosy and the eye. Community Eye Health 1989; 3: 2

4 Chovet $M$. Les lesions oculaires de la lepre lepromateuse. f Fr Ophtalmol 1980; 3: 473.

5 Shorey P. Ocular changes in reactions in leprosy. Lepr Rev 1989; 60: 102.

6 Krassai A, Corneal sensitivity in lepromateous leprosy. Int $\mathcal{J}$ Lepr 1970; 38: 422.

7 Karaçorlu M, Çakiner T, Saylan T. Corneal sensitivity and correlations between decreased sensitivity and anterior segment pathology in ocular leprosy. $\mathrm{Br} f$ Ophthalmol 1992; 75: 117.

8 Lamba PA, Rohatgi J, Bose S. Factors influencing corneal involvement in leprosy. Int $\mathscr{f}$ Lepr 1987; 55: 667.

9 Leiker PL. Classification of leprosy. Lepr Rev 1966; 37-I: 7.

10 Medical Research Council War Memorandum. Aids to the investigation of peripheral nerve injuries. Memo 7. 2nd ed. London: MRC, 1962.

11 Boberg-Ans J. On the corneal sensitivity. Arch Ophthalmol 1956; 34: 149,

12 Boberg-Ans J. Experience in clinical examination of corneal sensitivity. Br f Ophthalmol 1955; 39: 705.

13 Cochet M, Bonnet R. L'esthésiométrie cornéenne. Bull Soc d'Ophtalmol 1961; 61: 541 .

14 Millodot M. A review of research on the sensitivity of the cornea. Ophthalmic Physiol Opt 1984; 4: 305.

15 Draeger J. Zur ästhesiometrie der hornhaut. Klin Monatsbl Augenheilkd 1976; 169: 407.

16 Larson WL. Electro-mechanical corneal aesthesiometer. Br f Ophthalmol 1970; 54: 342.

17 Beuerman RW. Comparative clinical assessment of corneal sensation with a new aesthesiometer. Am $\mathcal{F}$ Ophthalmol 1978; 86: 812 .

18 Millodot $M$. The influence of age on the sensitivity of the cornea. Invest Ophthalmol Vis Sci 1977; March: 240.

19 Ackermann-Körner M, Draeger J. Quantitative Messungen der Hornhautsensibilität bei idiopatischer Trigeminusneuralgie und nach Neurochirurgischen Eingriffen am N. Trigeminus. Klin Monatsbl Augenheilkd 1991; 199:

84 Karvounis PC, Frangos E. Some new aspects of the nerve
supply of the cornea and conjunctiva [Monograph] Human Genet 1970; 6: 206 .

21 Hogeweg M, Kiran KU, Suneetha S. The significance of facial patches in relation to recent facial nerve damage in leprosy. Lepr Rev 1991; 62-2: 143.

22 Lyne AJ. Corneal sensitivity in scleritis and episcleritis. $\mathrm{Br} \mathcal{F}$ Ophthalmol 1977; 61: 650 . 